\title{
Prevalence and determinants of cigarette smoking among college students: a cross- sectional study in Douala, Cameroon
}

\author{
Bertrand Hugo Mbatchou Ngahane ${ }^{1,2^{*}}$, Huguette Atangana Ekobo ${ }^{2}$ and Christopher Kuaban ${ }^{3}$
}

\begin{abstract}
Background: Tobacco is the most important avoidable risk for non communicable diseases. While tobacco consumption is stable or declining in developed countries, it is increasing in the developing world with a rate of $3.4 \%$ per annum. The objective of this study was to estimate the prevalence and factors associated with cigarette smoking among college students.

Methods: A cross-sectional study was conducted from December 2012 to April 2013 in secondary schools in Douala, Cameroon. A self-administered questionnaire was used to collect sociodemographic data, smoking behavior and peer smoking among college students. Logistic regression analyses was employed to identify factors associated with cigarette smoking.

Results: Of a total of 2623 students included, 1579 (60.2 \%) were female. The mean age of participants was $19.2 \pm 2.53$ years. The prevalence of current smoking was $11.2 \%$ [95 \% confidence interval (Cl) $10-12$ ], with $20 \%$ in males and $5.3 \%$ in females. Cigarette smoking was with significantly associated with friends smoking [Odds ratio (OR) $6.66 ; 95 \% \mathrm{Cl} 4.69$ - 9.45)], male gender (OR 3.61; $95 \% \mathrm{Cl} 2.52$ - 5.16), increase in age (OR 1.10; 1.03 - 1.17), parental smoking 1.69 (1.04 - 2.76), and attending general education (OR 1.85; 1.23 - 2.78).

Conclusions: Cigarette smoking constitutes a significant health hazard in college students in Douala. Youth population and especially male students should be continuously targeted by preventive measures and sensitization campaigns against tobacco use. Parents should be aware on the influence of their smoking behavior on initiation of smoking in their children and should be encouraged to quit smoking.
\end{abstract}

Keywords: Tobacco, Prevalence, College students, Africa

\section{Background}

Tobacco smoking remains a serious threat to global health, killing nearly 6 million people each year and causing excessive health-care costs and lost productivity [1]. About $80 \%$ of the more than one billion smokers worldwide live in low- and middle-income countries, where the burden of tobacco-related illness and death is heaviest [1]. While tobacco consumption is stable or declining in developed countries, it is increasing in the developing world with a rate of $3.4 \%$ per annum [2]. A recent study on projection

\footnotetext{
* Correspondence: mbatchou.ngahane@yahoo.com

'Department of Internal Medicine, Douala General Medicine, PO Box 4856,

Douala, Cameroon

${ }^{2}$ Faculty of Medicine and Pharmaceutical Sciences, University of Douala,

Douala, Cameroon

Full list of author information is available at the end of the article
}

of tobacco use predicted a worsening of tobacco epidemics in countries of Africa and eastern Mediterranean where health system are fragile [3]. Youth and women are the main targets of tobacco industries in these countries as they are developing economically [4]. Tobacco is the most important avoidable risk for non communicable diseases (NCDs) such as cancers, chronic lung disease, diabetes and cardiovascular diseases [1]. With the increasing prevalence of smoking in developing world over the years, NCDs will double the burden of infective and noninfective diseases [2].

The Global Youth Tobacco Survey (GYTS) which was designed by the Center for Disease Control and Prevention and the World Health Organization estimated the worldwide burden of tobacco use among youth [5]. The

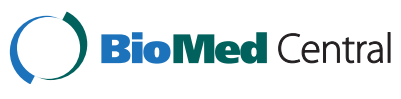

(C) 2015 Mbatchou Ngahane et al. Open Access This article is distributed under the terms of the Creative Commons Attribution 4.0 International License (http://creativecommons.org/licenses/by/4.0/), which permits unrestricted use, distribution, and reproduction in any medium, provided you give appropriate credit to the original author(s) and the source, provide a link to the Creative Commons license, and indicate if changes were made. The Creative Commons Public Domain Dedication waiver (http://creativecommons.org/publicdomain/zero/1.0/) applies to the data made available in this article, unless otherwise stated. 
results of this survey which included school children from 131 countries showed a global prevalence of $8.9 \%$ for current smoking students. This prevalence was highest in the WHO Region of the Americas (17.5\%) and the WHO European Region $(17.9 \%)$ and less than $10 \%$ in the four other WHO regions [5]. In Ethiopia, the GYTS collaborative group reported $4.5 \%$ of prevalence of smoking in males and $1 \%$ in females aged 13-15 years [6]. In Cameroon, a country without any tobacco control legislation, the prevalence of smoking is relatively low [7]. The GYTS reported a cigarette smoking prevalence of $5.7 \%$ among college students aged 13-15 years [8]. It has been shown that children who start smoking during a younger age are more likely to smoke as adults than individuals who begin at older ages [9]. Therefore, though it is important to determine the burden of tobacco use in this age group, it is also necessary to investigate its associated factors in order to design efficient preventive programs against tobacco consumption. Only few studies have investigated the factors associated with tobacco use among school adolescents in sub-Saharan Africa [10-12] and we didn't find any related study in Cameroon. We therefore aimed in this study to estimate the prevalence and associated factors of cigarette smoking in college students.

\section{Methods}

\section{Study design and setting}

A cross-sectional study was conducted in secondary schools in Douala from $1^{\text {st }}$ December 2012 to April 30, 2013. Douala is the economic capital and the largest biggest city of Cameroon. It is also the headquarters of the Littoral region and the population was estimated at 1907479 inhabitants in 2005 [13]. In Cameroon, secondary education which follows the 6 years of primary education has a 7 years duration and is divided into 2 cycles: the $1^{\text {st }}$ cycle which comprises the 4 first years of studies and the 3 last years of the secondary education constitute the $2^{\text {nd }}$ cycle [14]. Students are allowed to choose technical and vocational education or general education. They can register either in a private or public school.

\section{Participants and sampling}

We conveniently choose to include students attending the second cycle of secondary education. Of a total of 300 secondary schools in the city of Douala, 85 of them were excluded because they had only the first 4 years of secondary education. We finally had 215 eligible schools. Eligible students were those present in class during our visit in schools. Non consenting students were excluded.

We used a multistage probability proportional to size stratified sampling procedure with the school being the primary sampling unit. In the first stage, the strata were defined according to the type of education (general vs technical and vocational) and the status (public vs private). We thus had 4 strata: public general (20 schools), private general (118 schools), public technical and vocational (6 schools) and private technical and vocational (71 schools). These schools were randomly selected in proportion to their size, giving respectively 3, 20, 1 and 12 schools for the above strata. In the second stage, 2 classes were randomly selected in each school and finally, in each class, all students were invited to participate in the study.

The study was approved by the Cameroon's National Ethics Committee. In addition, we got administrative authorizations from the Ministry of Secondary Education and the school authorities. Parents of students aged less than 18 years were also informed about the scope of the study and gave a verbal consent before the recruitment of their children in the study.

\section{Data collection}

The selected students were given a self-administered anonymous questionnaire in their classroom during breaks. Teachers were asked to leave the classroom during the survey administration and the data collection was supervised by a trained investigator who was present in the class. He collected the forms as soon as they were filled by the students.

The questionnaire assessed the sociodemographic data (age, gender, year of education), number of classes repeated, smoking behavior (smoking status, reason of smoking, smoking during the last 30 days), smoking status of family members and friends, knowledge of tobacco hazards. For the latter, participants were asked to give a yes or no response for the question if they knew some negative effect of tobacco health, without giving the details of this hazards. The Fagerström score of nicotine dependence was accessed in smokers. A score smaller than 3 indicates low dependence while a score between 3 and 6 indicates moderate dependence and a score between 7 and 10 reflects a high nicotine dependence [15].

The dependent variable in this study was the smoking status. Were considered as current smokers in this study, students smoking at least one cigarette per month. Daily smokers were those smoking at least one cigarette per day, weekly smokers were those smoking 1 to 6 cigarettes per week, ,while occasional smokers or monthly smokers were those smoking 1 to 3 cigarettes per month. The exposure variables were: age, gender, type of education (general vs technical), school status (private vs public), number of classes repeated, parental smoking, peer smoking and knowledge of health effect of smoking.

\section{Statistical analysis}

Data were entered and analyzed using IBM SPSS statistics Version 20 (Armonk, NY: IBM Corp). Descriptive 
statistics included frequencies and proportions for categorical data and means with standard deviations (SD) for continuous data. Logistic regression analysis was used to assess the factors associated with smoking. A univariate analysis was firstly performed to estimate crude odds ratios and their $95 \%$ confidence intervals (95\% CI). Variables found to be significantly associated in univariate analysis were considered in the multivariable models using a stepwise backward elimination procedure. A $p$-value less than 0.05 was considered to be statistically significant.

\section{Results}

\section{General characteristics of participants}

Of a total of 3170 students who completed the survey, exploitable data were available for 2623 (82.7\%) respondents. Of them, 1579 (60.2\%) were female and 1044 (39.2 \%) were male. The mean age of the participants was $19.2 \pm 2.53$ years (range $12-29$ ). Students aged between 15 and 19 years were the most represented $(55.7 \%)$. The mean number of classes repeated by students was $1.28 \pm 0.97$. The other baseline characteristics of participants are showed in Table 1.

\section{Smoking status of participants}

One third of the respondents (33.5\%) had ever smoked a cigarette while the prevalence of current cigarette smoking was $11.2 \%$ (95\% CI 10 - 12) with $8.4 \%$ being regular smokers and $2.8 \%$ occasional smokers. The male prevalence $(20 \%)$ of cigarette smoking was significantly higher than that of females $(5.3 \%)(P=0.000)$. The mean age at starting smoking of cigarettes was $14.6 \pm 3.8$ (range 6 - 24) and 270 (10.3\%) smoked at least one cigarette in the last 30 days prior the study. Among the 293 cigarette smokers, the Fagerström score for nicotine dependence was high for $18.4 \%$ of them, moderate for $46.4 \%$ and low for $35.2 \%$. The main reasons of starting smoking were curiosity (92.1\%), pleasure (91.8\%) and stressful situations $(90.4 \%)$. Table 2 shows the other attitudes of smoking students.

\section{Risk factors of cigarette smoking}

The univariate analysis revealed that male sex, age, attending general education, number of classes repeated, parental smoking, family smoking and friends smoking were associated with current smoking status (Table 3). After adjusting these variables to each other in the multivariate analysis, the most important risk factors for cigarette smoking was friends smoking (OR 6.66; $95 \%$ CI 4.69 - 9.45). It was followed by male sex (OR 3.61; $95 \%$ CI 2.52 - 5.16). An increase in age was also associated with smoking as well as parental smoking and attending a general education system (Table 4).
Table 1 General characteristics of participants $(n=2623)$

\begin{tabular}{|c|c|}
\hline Variables & Number (\%) \\
\hline \multicolumn{2}{|l|}{ Gender } \\
\hline Male & $1044(39.8 \%)$ \\
\hline Female & $1579(60.2 \%)$ \\
\hline \multicolumn{2}{|l|}{ Age } \\
\hline$<15$ years & $45(1.7 \%)$ \\
\hline $15-19$ years & $1461(55.7 \%)$ \\
\hline $20-24$ years & $1057(40.3 \%)$ \\
\hline $25-29$ years & $60(2.3 \%)$ \\
\hline \multicolumn{2}{|l|}{ Year of education } \\
\hline $5^{\text {th }}$ & $415(15.8 \%)$ \\
\hline $6^{\text {th }}$ & $1336(50.9 \%)$ \\
\hline $7^{\text {th }}$ & $872(33.3 \%)$ \\
\hline \multicolumn{2}{|l|}{ Have ever smoked a cigarette } \\
\hline Yes & $879(33.5 \%)$ \\
\hline No & $1744(66.5 \%)$ \\
\hline \multicolumn{2}{|l|}{ Have repeated a class } \\
\hline Yes & $1972(75.2 \%)$ \\
\hline No & $651(24.8 \%)$ \\
\hline \multicolumn{2}{|l|}{ Type of education } \\
\hline General & $1868(71.2 \%)$ \\
\hline Technical and vocational & $755(28.8 \%)$ \\
\hline \multicolumn{2}{|l|}{ School status } \\
\hline Public & $395(15.1 \%)$ \\
\hline Private & $2228(84.9 \%)$ \\
\hline \multicolumn{2}{|c|}{ Knowledge of warmful effects smoking } \\
\hline Yes & $2070(78.9 \%)$ \\
\hline No & $553(21.1 \%)$ \\
\hline \multicolumn{2}{|l|}{ Smoked the last 30 days } \\
\hline Yes & $270(10.3 \%)$ \\
\hline No & $2353(89.7 \%)$ \\
\hline \multicolumn{2}{|l|}{ Smoking status } \\
\hline Non smoker & $2330(88.8 \%)$ \\
\hline Regular smoker & $221(8.4 \%)$ \\
\hline Occasional smoker & $72(2.8 \%)$ \\
\hline
\end{tabular}

\section{Discussion}

In this survey on smoking habits of college students in Cameroon, we found that the prevalence of cigarette smoking among college students was $11.2 \%$. The main predictors of cigarette smoking were having friends who smoke, male sex, age, parental smoking and attending general education.

Whatever the case this prevalence is higher than $5.7 \%$ found in GYTS survey in Cameroon in 2008 [8]. May be the prevalence of smoking is increasing with the years, but we should notice that the GYTS study involved 
Table 2 Attitudes towards smoking of cigarette smoking students $(n=293)$

\begin{tabular}{ll}
\hline Characteristics & Number (\%) \\
\hline Fagerström score & $103(35.2 \%)$ \\
Low (0-2) & $136(46.4 \%)$ \\
Moderate (3-6) & $54(18.4 \%)$ \\
High (7-10) & \\
Place of smoking & $78(26.6 \%)$ \\
At home & $46(15.6 \%)$ \\
In school & $112(38.2 \%)$ \\
When with smokers & $231(78.8 \%)$ \\
During recreative parties & \\
Reason of starting smoking & $254(86.6 \%)$ \\
Imitation & $265(90.4 \%)$ \\
Stress & $270(92.1 \%)$ \\
Curiosity & $270(92.1 \%)$ \\
Pleasure & $151(51.5 \%)$ \\
Advertisement & $171(58.3 \%)$ \\
Want to quit smoking & \\
Reason of the desire to quit smoking $(n=171)$ & $121(70.7 \%)$ \\
Save money & $161(94.1 \%)$ \\
Keep a good health & $156(91.2 \%)$ \\
Self discipline & $132(45 \%)$ \\
Have stopped smoking in the past &
\end{tabular}

adolescents of 13 to 15 years while our study included college students with an elder age. It has been demonstrated that the prevalence of smoking increases with age among youths [16-18]. Our prevalence is similar to that of a study conducted in Ethiopia among college students aged 15 to 25 years which showed $12.2 \%$ of smokers [12].

Having smoking friends in this study was the most important independent factor associated with cigarette smoking. Reports from different regions of the world found similar results [17, 19-22]. Evidence from two longitudinal studies conducted in the United States showed that non-smoking adolescents who have friends who smoke are more likely to start smoking in the future than those without any smoking friends [23, 24]. We also found that parental smoking was associated with smoking among college students. The critical influence of parental smoking on adolescent's smoking behavior was demonstrated by Bricker et al. in a cohort study involving five thousand families [25]. This finding is consistent with the results of other studies carried out in developing countries as well as in industrialized countries [26]. In fact, children are more likely to reproduce the behaviors and attitudes of their parents who are considered by them as models. Secondly, as demonstrated by Scragg et al., parents who smoke are more likely to allow smoking in the house [27]. Students living with another family member who smoke had a twofold risk of being smokers than those living with non-smokers. Similar results were recently found by Shadid and Hossain in Jordan [28].

In this study, the influence of smoking of peers on the smoking status of students was greater than that of parental smoking. Similar results were reported in previous studies in sub-Saharan Africa [6, 29]. On contrary, although a study conducted in 27 European countries reported parental smoking and smoking of peers as factors associated with smoking initiation, the effects of these two factors were similar [30].

Male sex was strongly associated with cigarette smoking. The same results have been found in other African countries $[12,22,26]$ and in studies carried out in middle East and in South East Asia [26, 28, 31]. On the contrary, in developed countries, the disparity between male and female prevalence is smaller [32]. These data show the difference in social-cultural habits of different parts of the world. However, data concerning smoking prevalence in women in Africa may be underreported, especially in areas where smoking of women is not culturally accepted and is socially regarded as a pejorative behavior [26].

We detected an association between age and cigarette smoking in the present study. An increase in age was increasing the odds of smoking. Although this association has not been revealed by most of the studies, it was reported by some studies [12, 16, 18, 33]. One possible explanation for this finding is that during adolescence, the self-affirmation of adolescents and their risk behavior increase with increasing age. Consequently, at the late adolescence, there is a high risk of smoking [34, 35].

Attending general secondary education was another factor associated with cigarette smoking. The type of education as factor associated with smoking among students has not been well studied. However, our result is similar to that of Mohammad in Iran [36] but contrary to that of Nowicka-Sauer et al. in Poland who identified technical high school as a predictor of tobacco smoking [37]. Further studies are needed to investigate the role of technical or general education in the initiation of smoking among students.

The strengths of this study are the large sample of students and the sampling methods which participate to the accuracy of our results. This is confirmed by the narrowed confidence intervals that we obtained in the multivariate regression analysis.

Meanwhile, there are some limitations in this study. First, the prevalence of smoking may have been underestimated by negative responses from students who smoke secretly. Meanwhile, $17.3 \%$ of students were excluded in this study because of they didn't answer to key questions. 
Table 3 Univariate analysis of factors associated with current cigarette smoking among college students in Douala

\begin{tabular}{|c|c|c|c|c|}
\hline \multirow[t]{2}{*}{ Variables } & \multicolumn{2}{|c|}{$\underline{\text { Cigarette smoking }}$} & \multirow[t]{2}{*}{$P$ value } & \multirow{2}{*}{$\begin{array}{l}\text { Crude OR } \\
(95 \% \mathrm{Cl})\end{array}$} \\
\hline & Yes $(n=293)$ & No $(n=2330)$ & & \\
\hline \multicolumn{5}{|l|}{ Gender } \\
\hline Male & $209(20 \%)$ & $836(80 \%)$ & 0.000 & $4.45(3.38-5.85)$ \\
\hline Female (ref) & $84(5.3 \%)$ & $1494(94.7 \%)$ & & \\
\hline Age, per year increase & & & 0.000 & $1.12(1.07-1.18)$ \\
\hline \multicolumn{5}{|l|}{ Type of education } \\
\hline General school & $239(12.8 \%)$ & $1629(87.2 \%)$ & 0.000 & $1.90(1.39-2.59)$ \\
\hline Technical school (ref) & $54(7.2 \%)$ & $701(92.8 \%)$ & & \\
\hline \multicolumn{5}{|l|}{ School status } \\
\hline Public school & $42(10.6 \%)$ & $353(89.4 \%)$ & 0.71 & $0.93(0.66-1.32)$ \\
\hline Private school (ref) & $251(11.3 \%)$ & 1977 (88.7 \%) & & \\
\hline Number of class repeated & & & 0.000 & $1.30(1.13-1.48)$ \\
\hline \multicolumn{5}{|l|}{ Parental smoking } \\
\hline Yes & 85 (25.4\%) & $250(74.6 \%)$ & 0.000 & $3.4(2.55-4.51)$ \\
\hline No (ref) & $208(9.1 \%)$ & $2080(90.9 \%)$ & & \\
\hline \multicolumn{5}{|l|}{ Family smoking } \\
\hline Yes & 133 (18.8 \%) & $576(81.2 \%)$ & 0.000 & $2.84(2.2-3.66)$ \\
\hline No (ref) & $160(8.3 \%)$ & $1754(91.6 \%)$ & & \\
\hline \multicolumn{5}{|l|}{ Friends smoking } \\
\hline Yes & $242(31.6 \%)$ & $523(68.4 \%)$ & 0.000 & $9.9(7.46-13.15)$ \\
\hline No (ref) & $51(2.7 \%)$ & $1807(97.3 \%)$ & & \\
\hline \multicolumn{5}{|c|}{ Knowledge of warmful effects smoking } \\
\hline Yes & $233(11.3 \%)$ & $1837(88.7 \%)$ & 0.55 & $1.10(0.79-1.51)$ \\
\hline No (ref) & $60(10.9 \%)$ & $493(89.1 \%)$ & & \\
\hline
\end{tabular}

Table 4 Multivariate analysis of factors associated with cigarette smoking among college students in Douala

\begin{tabular}{|c|c|c|c|}
\hline Variables & Cigarette smoking $(n=293)$ & aOR $(95 \% \mathrm{Cl})$ & $P$-value \\
\hline \multicolumn{4}{|l|}{ Gender } \\
\hline Male & 209 (20 \%) & $3.61(2.52-5.16)$ & 0.000 \\
\hline Female & $84(5.3 \%)$ & & \\
\hline Age, per year increase & - & $1.10(1.03-1.17)$ & 0.002 \\
\hline \multicolumn{4}{|l|}{ Type of education } \\
\hline General school & $239(12.8 \%)$ & $1.85(1.23-2.78)$ & 0.003 \\
\hline Technical school & $54(7.2 \%)$ & & \\
\hline Number class repeated, increase & - & $1.04(0.0 .87-1.25)$ & 0.62 \\
\hline \multicolumn{4}{|l|}{ Parental smoking } \\
\hline Yes & 85 (25.4\%) & $1.69(1.04-2.76)$ & 0.03 \\
\hline No & 208 (9.1\%) & & \\
\hline \multicolumn{4}{|l|}{ Family smoking } \\
\hline Yes & $133(18.8 \%)$ & $1.48(0.97-2.26)$ & 0.06 \\
\hline No & $160(8.3 \%)$ & & \\
\hline \multicolumn{4}{|l|}{ Friends smoking } \\
\hline Yes & $242(31.6 \%)$ & $6.66(4.69-9.45)$ & 0.000 \\
\hline No & $51(2.7 \%)$ & & \\
\hline
\end{tabular}


The prevalence of smoking might have been increased or decreased if they had responded properly to these questions. In addition, some factors such as psychosocial factors, the influence of media were not assessed.

In conclusion, although the prevalence of smoking among college students in Douala is low, it may increase if there is no efficient action against tobacco use in Cameroon. Male sex, parental and peer smoking are the main predictors of smoking among youths. There is a need to design and implement effective preventive measures against tobacco use. In addition to college students, smoking families should be targeted by these programs.

\section{Competing interest}

The authors declare that they have no competing interest.

\section{Authors' contributions}

MNBH conceived the study, analyzed the data and drafted the manuscript. AEH collected the data and $\mathrm{KC}$ revised the study protocol and the manuscript. All authors read and approved the final manuscript

\section{Acknowledgements}

The authors thank the Pan African Thoracic Society MECOR course staff for their contribution during the preparation of the manuscript.

\section{Author details}

'Department of Internal Medicine, Douala General Medicine, PO Box 4856, Douala, Cameroon. ${ }^{2}$ Faculty of Medicine and Pharmaceutical Sciences, University of Douala, Douala, Cameroon. ${ }^{3}$ Faculty of Health Sciences, University of Bamenda, Bamenda, Cameroon.

Received: 8 June 2015 Accepted: 24 September 2015 Published online: 21 December 2015

\section{References}

1. World Health Organization. WHO Report on the global tobacco epidemic, 2015. Geneva, Switzerland: WHO; 2015.

2. Boutayeb A, Boutayeb $S$. The burden of non communicable diseases in developing countries. International Journal for Equity in Health. 2005 Jan 14;4(1):2.

3. Bilano V, Gilmour S, Moffiet T, d'Espaignet ET, Stevens GA, Commar A, et al. Global trends and projections for tobacco use, 1990-2025: an analysis of smoking indicators from the WHO Comprehensive Information Systems for Tobacco Control. Lancet. 2015;385(9972):966-76.

4. Lee S, Ling PM, Glantz SA. The vector of the tobacco epidemic: tobacco industry practices in low and middle-income countries. Cancer Causes Control. 2012;23 Suppl 1:117-29.

5. Warren CW, Jones NR, Eriksen MP, Asma S. Patterns of global tobacco use in young people and implications for chronic disease disease burden in adults. Lancet. 2006;367(9512):749-53.

6. Rudatsikira E, Abdo A, Muula AS. Prevalence and determinants of adolescent tobacco smoking in Addis Ababa, Ethiopia. BMC Public Health. 2007;7:176.

7. Ng M, Freeman MK, Fleming TD, Robinson M, Dwyer-Lindgren L, Thomson B, et al. Smoking prevalence and cigarette consumption in 187 countries, 1980-2012. JAMA. 2014 Jan 8;311(2):183-92.

8. Awono PM, Sibetcheu D. Enquête globale sur le tabagisme en Milieu jeune. "GYTS 2008". Rapport MINSANTE 2008.

9. Chassin L, Presson CE, Sherman SJ, Edwards DA. The natural history of cigarette smoking: predicting young adult smoking outcomes. Health Psychol. 1990;9:701-16.

10. Koueta F, Dao L, Ye D, Koura M, Sawadogo A. Factors contributing to smoking among students in Ouagadougou (Burkina Faso). Rev Mal Respir. 2009;26(3):291-7.

11. Panday S, Reddy SP, Ruiter RA, Bergstrom E, de Vries H. Determinants of smoking among adolescents in the Southern Cape-Karoo region, South Africa. Health Promot Int. 2007;22(3):207-17.
12. Reda AA, Moges A, Yazew B, Biadgilign S. Determinants of cigarette smoking among school adolescents in eastern Ethiopia: a cross-sectional study. Harm Reduct J. 2012;9:39.

13. UN data. City population by sex, city and city type. 2015. Available from: data.un.org. Accessed 12 May 2015.

14. Cameroon's National Institute of Statistics. Results of the second survey on monitoring public expenditure and beneficiaries' satisfaction in both the educational and health sectors. 2010. Available from: http://www.statisticscameroon.org/news.php?id=80. Accessed $2^{\text {nd }}$ March 2015.

15. Heatherton T, Fagerström KO. The Fagerström test for nicotine dependence. A revision of the Fagerström tolerance questionnaire. $\mathrm{Br} J$ Addiction. 1991;86:1119-27.

16. Rachiotis G, Muula AS, Rudatsikira E, Siziya S, Kyrlesi A, Gourgoulianis K, et al. Factors associated with adolescent cigarette smoking in Greece: results from a cross sectional study (GYTS Study). BMC Public Health. 2008;8:313.

17. Rudatsikira E, Dondog J, Siziya S, Muula AS. Prevalence and determinants of adolescent cigarette smoking in Mongolia. Singapore Med J. 2008 Jan;49(1):57-62.

18. Sanchez ZM, Opaleye ES, Martins SS, Ahluwalia JS, Noto AR. Adolescent gender differences in the determinants of tobacco smoking: a cross sectional survey among high school students in Sao Paulo. BMC Public Health. 2010;10:748.

19. Taylor JE, Conard MW, Koetting O'Byrne K, Haddock CK, Poston WS. Saturation of tobacco smoking models and risk of alcohol and tobacco use among adolescents. J Adolesc Health. 2004 Sep;35(3):190-6.

20. Rogacheva A, Laatikainen T, Patja K, Paavola M, Tossavainen K, Vartiainen E. Smoking and related factors of the social environment among adolescents in the Republic of Karelia, Russia in 1995 and 2004. Eur J Public Health. 2008;18(6):630-6.

21. Muula AS, Siziya S, Rudatsikira E. Prevalence and correlates of cigarette smoking among adolescents in Malawi: results from the Global Youth Tobacco Survey 2005. Tanzan J Health Res. 2008 Jul;10(3):166-76.

22. Siziya S, Rudatsikira E, Muula AS. Factors associated with current cigarette smoking among adolescents in Ville du Sud, Cote d'Ivoire. Mali Med. 2007;22(4):40-6.

23. Bricker JB, Peterson Jr AV, Andersen MR, Rajan KB, Leroux BG, Sarason IG. Childhood friends who smoke: do they influence adolescents to make smoking transitions? Addict Behav. 2006 May;31 (5):889-900.

24. Ary DV, Biglan A. Longitudinal changes in adolescent cigarette smoking behavior: onset and cessation. J Behav Med. 1988 Aug;11(4):361-82.

25. Bricker JB, Peterson Jr AV, Leroux BG, Andersen MR, Rajan KB, Sarason IG. Prospective prediction of children's smoking transitions: role of parents' and older siblings' smoking. Addiction. 2006 Jan;101(1):128-36.

26. World Health Organization. Gender, women, and the tobacco epidemic. Geneva2010; Available from: http://whqlibdoc.who.int/publications/2010/ 9789241599511_eng.pdf?ua=1. Accessed $2^{\text {nd }}$ March 2015.

27. Scragg $R$, Laugesen $M$, Robinson E. Parental smoking and related behaviours influence adolescent tobacco smoking: results from the 2001 New Zealand national survey of 4th form students. N Z Med J. 2003 Dec 12;116(1187):U707.

28. Shadid HM, Hossain SZ. Smoking behaviour, knowledge and perceived susceptibility to lung cancer among secondary-school students in Amman, Jordan. East Mediterr Health J. 2015;21(3):185-93.

29. Mbatchou Ngahane BH, Luma H, Mapoure YN, Fotso ZM, Afane ZE. Correlates of cigarette smoking among university students in Cameroon. Int J Tuberc Lung Dis. 2013 Feb;17(2):270-4.

30. Filippidis FT, Agaku IT, Vardavas Cl. The association between peer, parental influence and tobacco product features and earlier age of onset of regular smoking among adults in 27 European countries. Eur J Public Health. 2015;25(5):814-8.

31. Pradhan PM, Niraula SR, Ghimire A, Singh SB, Pokharel PK. Tobacco use and associated factors among adolescent students in Dharan, Eastern Nepal: a cross-sectional questionnaire survey. BMJ Open. 2013;3(2). doi:10.1136/bmjopen-2012-002123.

32. World Health Organization. WHO report on the global tobacco epidemic: Implementing smoke-free environments. Geneva: WHO; 2009.

33. Institut national de prévention et d'éducation pour la santé. Baromètre santé 2010. Available from: http://www.inpes.sante.fr/Barometres/barometresante-2010/index.asp. Accessed 12 May 2015. 
34. Escobedo LG, Reddy M, DuRant RH. Relationship between cigarette smoking and health risk and problem behaviors among US adolescents. Arch Pediatr Adolesc Med. 1997 Jan;151(1):66-71.

35. Petridou E, Zavitsanos X, Dessypris N, Frangakis C, Mandyla M, Doxiadis $S$, et al. Adolescents in high-risk trajectory: clustering of risky behavior and the origins of socioeconomic health differentials. Prev Med. 1997 Mar-Apr;26(2):215-9.

36. Mohammad-Alizadeh-Charandabi S, Mirghafourvand M, Tavananezhad N, Karkhaneh M. Prevalence of cigarette and water pipe smoking and their predictors among Iranian adolescents. Int J Adolesc Med Health. 2015;27(3):291-8

37. Nowicka-Sauer K, Laska M, Sadlak-Nowicka J, Antkiewicz H, Bochniak M. Tobacco smoking problem in a group of 18-year-old high school students in the city of Gdansk-finding causes and preventive methods. Adv Med Sci. 2006;51 Suppl 1:145-50.

\section{Submit your next manuscript to BioMed Central and take full advantage of:}

- Convenient online submission

- Thorough peer review

- No space constraints or color figure charges

- Immediate publication on acceptance

- Inclusion in PubMed, CAS, Scopus and Google Scholar

- Research which is freely available for redistribution 